\title{
Creating a Digital Archive for Students' Research in a Credit Library Course
}

Using wiki technology in a credit library course, the authors created an online exhibit for students' research entitled the Digital Archive. The purpose of the Digital Archive is to showcase students' final projects from the course and to demonstrate research skills developed during the semester. It is an ongoing and evolving endeavor between students and instructors, and it will continue as a source of scholarly communication. The authors discuss the use of wiki technology, students' reactions, and lessons learned. Derived from student surveys, course evaluations, and instructor observations, the authors also present an assessment of the usefulness and effectiveness of using wiki technology to showcase coursework.

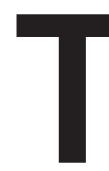

he University at Buffalo's (UB's) Arts and Sciences Libraries offers the semester-long, credit-bearing course ULC-257: Introduction to Library Research Methods. The course attracts students from their freshman through their senior years and from widely diverse academic disciplines. Teaching ULC-257 is an increasingly popular and effective way for instruction librarians to integrate themselves into educational curricula and to continue the advancement of information literacy on campus. Librarians teaching this course have the opportunity to use more creative, effective, and research-proven instructional methods than they are accustomed to using for traditional one-shot library instruction classes.

The course is designed to introduce students to the research process and also to library information sources at UB. Objectives for the course include the following:

- Students will become effective and efficient researchers and library users.

- Students will hone their abilities to analyze and critically evaluate information.

- Students will develop the skills necessary for becoming information savvy and for becoming lifelong learners. ${ }^{1}$

The ULC-257 course has been offered since the fall semester of 2003. The structure and content of the course, however, have changed only incrementally since its inception. The authors felt it was necessary to revise and revitalize ULC-257, and they began that process prior to the spring semester of 2008. Placing more emphasis on the students' final research projects was central to all of the changes implemented. Historically, librarians teaching

\section{Tiffany R. Walsh and Christopher V. Hollister}

Tiffany R. Walsh and Christopher V. Hollister are information literacy librarians with the University at Buffalo Libraries in Buffalo, New York. Submitted for review September 5, 2008; accepted for publication September 19, 2008.

Reference \& User Services Quarterly, vol. 48 , no. 4 , pp. $391-400$ (c) 2009 American Library Association. All rights reserved.

Permission granted to reproduce for nonprofit, educational use. 
the course suffuse their own creative ideas into the final project, though the basic template of it has remained unchanged. Details of the final project are provided later.

For the spring semester of 2008, the authors seized the opportunity to employ an emerging technology that would revitalize the course and, in particular, the final project. The intent of employing a new technology would be to address students' educational expectations and also meet their diverse and increasingly sophisticated learning styles. For reasons discussed below, the authors opted to create an online showcase of students' final research projects using wiki technology, and they named it the ULC-257 Digital Archive.

\section{LITERATURE REVIEW}

The literature is increasingly populated by works about the professional use of Internet-based communication tools. As a suite, these tools are commonly referred to as Web 2.0 applications, and they include blogs, podcasts, social networking spaces, and wikis. Together, the innovative nature of these applications and their popularity among students provide unique opportunities for library use, especially for teaching and learning. Ragains writes, "It seems incumbent on instructional librarians to use Web 2.0 effectively in educating students."

Pedagogical literature from various disciplines provides a modest, though growing, body of evidence that wikis in particular are being used for creative teaching and learning activities. Still, Achterman writes, "The potential for wikis as an educational tool remains largely untapped." Elgort et al. discuss this shortcoming and assert, "Research that addresses pedagogical benefits and pitfalls of using wikis as a collaborative learning tool . . . are still rather limited."4

The opportunities provided by wikis are manifold. Lamb lists the features of wiki technology that facilitate creative teaching and learning:

- They provide an opportunity to share unique information.

- They are collaborative.

- They allow for open editing.

- They do not require sophisticated coding.

- They are ever-evolving. ${ }^{5}$

Their collaborative nature is most often cited as the primary reason for adopting wikis. From library literature, Allan discusses the use of wikis for "sharing information and new experiences" gained during library instruction sessions, and also for the collaborative "creation of general library information handouts and subject-specific resource guides." Baldwin suggests the usefulness of wikis for librarians to share instructional resources. ${ }^{7}$ Still, library literature provides little evidence in terms of wikis and collaborative teaching and learning. From educational literature, Parker and Chao describe the wiki as a "collaboration tool that can be used to engage students in learning with others within a collaborative environment." Beldarrain expounds, "Instructional design frameworks must be adapted to purposely integrate student interaction using technology tools. This requires using flexible models that allow designers to begin at any given point in the process, anchoring the use of technology on collaborative instructional strategies that lead the student toward achieving the desired learning outcomes."

Skiba touts wikis for enabling students to transmit knowledge, collaborate in the creation of new knowledge, and become subject matter experts. ${ }^{10}$ Matthies et al. refer to this as collaborative discovery learning: "Discovery learning takes place most notably in problem solving situations where the student draws on his/her own experience and prior knowledge to discover the truths that are to be learned."11 Traditionally, this concept is associated with constructivist learning theory, which holds that learning is a personal, internal process. Beldarrain writes, "The versatility of social software and other collaboration tools available today support constructivist environments that seek to motivate, cultivate, and meet the needs of the 21st-century learner." ${ }^{12}$ However, Matthies et al. assert that "wikis have the ability to make this process very interpersonal, collaborative, and dynamic." ${ }^{\prime 3}$

The flexibility of wiki technology is put forth as a unique and useful feature. McPherson explains, "Students can use wikis to insert music, graphics, video, and photos in their writing and to communicate meanings that were once inaccessible or not fully expressed through the printed word."14 Additionally, the ability for students and instructors to track progress of wiki projects is touted. Achterman describes this function:

Wikis have a "History" option that allows users to view each change that has been made to an entry since its creation. This makes it possible for the teacher-librarian and classroom teacher to chart progress and identify places in the learning process that require more or less intervention-a useful feedback tool in instructional design. ${ }^{15}$ 
The notion of wikis and authorship is often discussed. Yan asserts, "Teachers who want their students to be able to work together in an online publishing environment and need collaborative editing tools for students look to the wiki. ${ }^{16} \mathrm{He}$ continues: "Giving students the ability to share their work in this way transforms them into authors and publishers."17 Building on this, McPherson writes, "Knowing that real people will be reading and possibly responding to their writing is often the impetus to motivate students to write with much more enthusiasm than they would when composing traditional research essays, in which the classroom teacher or teacher-librarian is the only audience." ${ }^{18}$

The ongoing nature of wiki publications is also discussed. Raman et al. suggest that, once a wiki has been created, it will continue, and it can be built upon as a knowledge repository. ${ }^{19}$ Beldarrain continues: "Wikis are thought to be more permanent and serious than blogs and may serve as repositories of knowledge." ${ }^{20}$ Matthies et al. describe their experience building a wiki as a "virtual repository of student work." ${ }^{21}$ Lamb and Johnson elaborate on the possibilities of wiki publications as electronic portfolios, portals, or resource aggregators. ${ }^{22}$ Zazzau presents the use of wiki technology in a credit library course, allowing students to work in teams and then to publish their coursework. ${ }^{23}$ This continues the trend of using wikis for student collaboration and group publishing.

The authors of the present paper considered all of the above when adopting wiki technology to create the Digital Archive for the credit library course they teach. The student-student collaborative aspect was changed to a model of instructorstudent collaboration. The Digital Archive was created as a showcase for students' final projects and also as an ongoing source of scholarly communication.

\section{THE FINAL PROJECT ON THE ULC-257 DIGITAL ARCHIVE}

\section{The Final Project}

The redesigned final project in ULC-257 is an annotated bibliography, supplemented by a short classroom presentation, on a topic of the student's choosing but also subject to the instructor's approval. Students must compile a fifteen-source bibliography in MLA style. The sources specified must include a primary source, a print and electronic reference source, two reputable websites, three books, two peer-reviewed journal articles, one newspaper article, another periodical article, and four other sources of the student's choosing. Students also have to include a thesis statement and a list of relevant core concepts, or keywords, for their topics. All of the information has to be placed on the student's individual project page within the Digital Archive.

\section{Technology Selection}

The authors considered a variety of Web 2.0 applications for the final project, and then narrowed the options down to blogs and wikis. Both tools have the potential to manage course content in a manner consistent with the authors' goals for the final project. Blogs in particular are popular with students, though several factors influenced the authors' decision to use wiki technology instead.

Individual blog postings are presented in a simple, chronological order, while wiki content is collaborative; the material displays in a manner that gives equal importance to each contributor. While the "comments" feature of a blog does allow for discourse between a student and his or her classmates, a wiki reflects each student's contribution to a class endeavor in a more meaningful way. A wiki tracks changes to content through the "history" feature, allowing the instructor to chart progress on a project, and it also facilitates interaction between the student and the instructor. The authors believed that adopting a wiki for the ULC-257 final project would not only benefit students by introducing new technology into the curriculum, but it would also act as an archive of class achievement in the form of permanent publication. Given their vision of the final project, the authors decided that a wiki would function best as the showcase for which the Digital Archive was conceived.

After considering the selection of free wikis available on the Web, the authors chose DokuWiki for the Digital Archive; at the time, DokuWikis were already in use on the UB Libraries website. UB Libraries' Web manager assisted in creating a branded template that coordinated with the design of other library pages.

\section{The ULC-257 Digital Archive}

Prior to the spring semester of 2008, the authors began developing the Digital Archive. They designed it to be inviting to both students and other researchers. An introduction welcomes users to the wiki, provides some history, and states the intended purpose of the project: 
The Digital Archive is an online exhibit of research projects from the course, ULC-257: Library Research Methods. The purpose of the Digital Archive is to showcase students' final projects from the course and to demonstrate research skills developed during the semester.

Created by course instructors [Tiffany Walsh and Christopher Hollister], the Digital Archive was launched during the spring semester of 2008. It is an ongoing and evolving endeavor between ULC-257 students and instructors, and it will continue as a source of scholarly communication. ${ }^{24}$

There are links on the introductory page to a basic template and also to a model of a completed final project. The basic template provides the skeletal structure of the annotated bibliography that students are expected to compile. The authors created the model page to demonstrate how the completed final project should appear. Links to specific academic semesters, which connect users to featured student projects, appear below.

\section{Revised Course Structure}

Course syllabi for both sections of ULC-257 taught by the authors were modified to integrate the Digital Archive into students' course work, including homework, assigned readings, and class lectures and activities. Previously, homework assignments simply required that students locate materials relevant to course modules (e.g., finding peerreviewed journal articles, identifying primary materials, distinguishing between print and electronic reference sources, etc). The authors redesigned the assignments so that retrieved materials would be relevant to students' final project topics. Students would later post citations and annotations for those materials on their page within the Digital Archive. Thus completed coursework would gradually accumulate throughout the semester, and, once students were introduced to the wiki, materials would be ready for their individual pages.

About halfway through the semester, one full class was devoted to teaching students about wiki technology. The authors impressed upon the students that this class was essential to attend in order to complete their final projects. During this class, the authors introduced the students to the Digital Archive, and the students were assisted in creating their own project pages. Subsequently, the students received a homework assignment in which they were required to locate a reputable website about their topic and place a citation to it on the wiki. The authors used the results of this homework assignment to gauge whether or not students' required additional bibliographic or technical assistance. For the remainder of the semester, students were responsible for developing the content of their annotated bibliographies, and completed projects were due on the last day of class. The instructors were able to monitor students' progress as they developed their pages on the wiki.

Given that the wiki is publicly viewable, the authors used the written consent form below to obtain students' permission for their final projects to be exhibited online in the ULC-257 Digital Archive:

$\mathrm{I}$ — agree to allow my ULC-257 Final Project to be exhibited online in the ULC-257 Digital Archive. I understand my work may also be archived and removed from public viewing at the discretion of the course instructors and Digital Archive administrators.

Signed: Date:

The authors decided to include the archival and removal disclaimer so that projects remaining on the Digital Archive beyond the semester were deemed to be of high scholarly caliber and worthy of ongoing exhibition. In addition, the remaining projects would be models for future students and other researchers. To maintain the integrity of the Digital Archive, the authors felt strongly the need to remove projects that were incomplete, contained inaccurate citations, or poorly crafted annotations. For students with high-quality projects, the result would be a permanent, publicly available publication that they could take pride in and point to in graduate school or employment applications. The authors hoped this would provide an impetus for students to present their work in the best manner possible. Issues of privacy were discussed thoroughly with students prior to them signing the written consent form. All but one student, from both sections of the course, readily signed the consent form and agreed to have their work publically viewable on the wiki.

\section{COURSE OUTCOMES}

To track students' mastery of course material and their use of the wiki, the authors administered preand posttests. The authors also asked students to complete a voluntary Digital Archive feedback form, describing in detail their experience with 
and impressions of the wiki. The authors also consulted university-administered course evaluations to obtain a sense of student experiences during the semester, with particular attention to the Digital Archive project. The original intent of the Digital Archive was to leverage educational technology to enhance student learning and to increase student awareness of the importance of libraries to their educational experience. Using the instruments cited previously, the authors hoped to assess student learning and awareness in a measurable way.

The pretest was a ten-question assessment to gauge the level of students' library research skills before coursework was introduced (see appendix A). The combined average score for both sections of the course was 67 percent correct. Two additional opinion questions were posed relating to students' perceptions of the importance of libraries and library instruction in the current academic environment. Students overwhelmingly indicated that library instruction should be a mandatory part of their early educational curricula. Results were mixed, however, when queried about the relevance of libraries with the advent of Web searching tools. A total of 41 percent of the students from both sections of the course indicated their belief that libraries are becoming obsolete.

The posttest (see appendix B) was a tenquestion assessment administered during the last week of classes. The authors deemed the quality of the completed Digital Archive pages to be an appropriate evaluation of the research skills students' developed over the course of the semester, and that is further addressed later. For this reason, the authors created the posttest to assess student perceptions of the research skills they acquired in ULC-257, the usefulness of the course itself, and their awareness of the importance of libraries to their educational experience. The authors believed that using the wiki in the course would affect all of these factors. Every student from both sections of the course responded that, after completing ULC257 , their research skills were either a little better or much better than before. Most students (91 percent) described their resulting level of library research expertise as either slightly above average or advanced. A total of 74 percent of students indicated their belief that there is more to library research than they thought prior to taking the course. Every student described the importance of academic libraries to students in the future as more important than today or very important.

The remaining posttest questions asked students for their observations of the ULC-257 course's content and structure. Most students (85 percent) from both sections of the course answered that, since completing ULC-257, their idea of conducting research in the library had changed. Every student indicated that they would recommend the course to other students, that the course would be useful to new or freshman students, that the course can help prepare students for their academic careers, that research skills learned in the course can be applied to different academic disciplines, and that the skills learned in the course are applicable to students after they have graduated.

The Digital Archive student feedback form (see appendix C) was a four-question survey also administered during the last week of classes. Every student from both sections of the course regarded using the wiki as either easy or average in terms of difficulty. All students were in favor of creating an online publication as an outcome of their coursework. Most students (86 percent) were accordingly comfortable having their coursework publically viewable on the Digital Archive.

For the final feedback form question, the authors asked, "What are your thoughts on using the Digital Archive in this course?" Students' responses to the question fell within three distinguishable categories: enhancement of course content, benefits of wiki organization, and achievement of publication and scholarship within a discipline. Students' comments relating to enhancement of course content included the following:

- "It [the Digital Archive] is a good way to get students actively involved in the course."

- "It makes the coursework more involving ... it's a great tool. I hope that ULC-257 will someday be a prerequisite for all incoming students."

- "I think it's a positive aspect to this course which has tied together the concepts we've been exploring this whole semester. I think it provides a level of interaction with classmates that is thoughtful and constructive."

Students' comments relating to benefits of wiki organization included the following:

- "I think it's a great way to display student work. It is also a convenient place to organize everything."

- "It is very helpful because it eliminates paperwork, and makes it easier to save material!"

- "I think it was an easy and convenient way of organizing our information."

Students' comments relating to achievement of publication and scholarship within a discipline included the following: 
- "It can help other students get a brief overview of my topic and also give others ideas to look up."

- "I think it was/is a wonderful [way] to showcase your student work. Also it shows how much [students] improved in your course."

- "I like having a publication. This wiki was a good way to ease into producing more scholarly works.... I worked hard on it, I like other people learning from my research."

- "It will be nice to have a lasting piece of work at the conclusion of a class. Usually all the hard work (particularly a final paper) is graded and forever lost! It's also a little nerve-wracking, but this can serve as motivation beyond a letter grade to do well."

- "While the 'paper' will still be the great academic judgment point, the wiki will be how the masses communicate important topics."

- "I couldn't be more proud of myself. It makes research more fun."

The authors also consulted university-administered course evaluations to obtain a sense of student experiences during the semester, with particular attention to the Digital Archive project. The scale of evaluation scores, or ratings, for course evaluation questions runs from 0 at the lowest to 5.0 at the highest. For the purpose of this paper, there are three student-rated items addressed: (1) The various elements of this course combined well in helping me learn, e.g., assignments, texts, readings, laboratory, course technology; (2) the classroom technology helped me learn; (3) this course improved my analytical thinking, creativity, technical skill, or competence. For each of the three questions above, both sections of ULC-257 were rated higher than all combined undergraduate courses taught at UB. For question 1, the authors' sections of the course received a combined ranking of 4.5 compared to 4.1 for all other university courses. For question 2, the authors' sections of the course received a combined ranking of 4.7 compared to 4.0 for all other university courses. For question 3, the authors' sections of the course received a combined ranking of 4.6 compared to 4.0 for all other university courses.

\section{DISCUSSION}

\section{The Effect of the Digital Archive}

The use of the Digital Archive in ULC-257 was an overall success for the course itself, for the students, and for the instructors. For the course, there is now a permanent online showcase of students' research projects that can be used to promote the educational role of the libraries. This sort of course-related outcome is encouraged by UB's administration as part of its long-term undergraduate initiatives. These initiatives emphasize the importance of undergraduate research, the creation of digital scholarship, and the development of student portfolios.

For the students, their feedback indicated that they had a positive experience working with the wiki. Learning and working with a new technology helped to meet students where they are and to address their varied learning styles. Students who successfully completed the final project came away from the course with an online publication that they can cite on their résumés, in graduate school applications, or for their own personal gratification.

For the instructors, the Digital Archive provided a unique opportunity for instructor-student collaboration, which builds upon the studentstudent model presented in the literature. The tracking ability of the wiki allowed the instructors to more closely monitor students' progress. The instructors were then able to dialogue with students about content and design expeditiously and on an ongoing basis. This dialogue was accomplished through e-mail and one-on-one meetings outside of class time.

The authors perceive that students' Digital Archive projects were of a higher quality than those of previous semesters in which completed final projects were submitted as word-processed documents. In particular, students consulted a wider variety of information sources, they were more skilled at correctly identifying required types of sources, they used cited references to find supplemental materials about the subject matter, and they composed more professional annotations. Students' feedback and instructors' experience suggest that higher-quality final projects resulted from the modified course structure as well as the publically viewable nature of their work. Additionally, the authors found that completed projects, based on the template provided, made for an easier grading process.

\section{Privacy}

The publically viewable nature of students' work may raise privacy concerns among librarians wishing to embark on similar wiki projects. Although publically accessible coursework is not a traditional undergraduate requirement, the authors assert that initiatives like this are a unique opportunity for students to showcase their scholarship in the 
digital age. Students who are uncomfortable with others seeing their work are free to withhold their consent, and their work will be removed from the wiki after the grading period. Developing and presenting students' final projects on the wiki until the end of the semester is deemed by the authors to be an important part of the coursework.

\section{Future Implications}

The authors plan to implement changes to the Digital Archive and related coursework in future semesters. Given that students submitted their projects in an electronic format, there were increased instances of academic dishonesty in the form of copying and pasting material. In particular, the authors found that a surprising number of students copied citations both from the online library catalog and from database search results rather than crafting proper citations in the assigned style. As well, the authors were disappointed that a few students lifted text from database abstracts instead of creating original annotations. In the future, the authors will provide more instruction on what plagiarism is, how to avoid it, and the importance of citing sources properly.

Rules for the organization and inclusion of students' pages on the wiki will also change. Students will be instructed that those who earn a letter grade of A on their final projects will have their pages featured in a showcase area of the Digital Archive. Other projects will remain indexed on the wiki. However, the authors will change the students' written consent form to indicate that incomplete projects or those that contain plagiarism will be removed.

Additional changes to be implemented include using the wiki itself to provide immediate feedback to students. Instructors will leave feedback and guidance directly on students' wiki pages, using different font colors or other distinguishing features, rather than sending out a separate e-mail message. One-on-one meetings will continue to be an important part of the instructor-student collaboration.

\section{CONCLUSIONS}

Based on their experience with the Digital Archive and on their students' feedback, the authors feel confident in stating that employing wiki technology can be useful and effective in a credit library course. The success of this project has encouraged other ULC-257 instructors to incorporate it into their assigned coursework. The authors intend to continue growing the Digital Archive as a permanent showcase of students' scholarly accomplishments.

\section{ACKNOWLEDGEMENTS}

The authors gratefully acknowledge the technical and instructional assistance of their colleagues Scott Hollander and Bridget Schumacher in helping make the Digital Archive a reality.

\section{References}

1. Christopher Hollister, "Making the Case for Enhanced Learning: Using Case Studies in a Credit-Bearing Library Course," in An Introduction to Instructional Services in Academic Libraries, ed. Elizabeth Connor (New York: Haworth, 2008): 95-105.

2. Patrick Ragains, "Web 2.0: Opportunities for Information Literacy Instruction," Communications in Information Literacy 2, no. 1 (Spring 2008): 3-5. Available at: http://comminfolit.org/index.php/cil/issue/view/ Spring2008.

3. Doug Achterman, "Beyond Wikipedia," Teacher Librarian 34, no. 2 (Dec. 2006): 19.

4. Irina Elgort et al., "Is Wiki an Effective Platform for Group Course Work?" Australasian Journal of Educational Technology 24, no. 2 (2008): 195.

5. Annette Lamb and Larry Johnson, "An Information Skills Workout: Wikis and Collaborative Writing," Teacher Librarian 34, no. 5 (June 2007): 57-59.

6. Charles Allan, "Using a Wiki to Manage a Library Instruction Program: Sharing Knowledge to Better Serve Patrons," College E Research Libraries News 68, no. 4 (Apr. 2007): 242-44.

7. Virginia Baldwin, "Using New Technologies for Library Instruction in Science and Engineering: Web 2.0 Applications," Science \& Technology Libraries 27, no. 3 (2007): 91-99.

8. Kevin R. Parker and Joseph T. Chao, "Wiki as a Teaching Tool," Interdisciplinary Journal of Knowledge and Learning Objects 3 (2007): 57.

9. Yoany Beldarrain, "Distance Education Trends: Integrating New Technologies to Foster Student Interaction and Collaboration," Distance Education 27, no. 2 (Aug. 2006): 143.

10. Diane J. Skiba, "Do Your Students Wiki?" Nursing Education Perspectives 26, no. 2 (Mar./Apr. 2005): 120-21.

11. Brad Matthies et al. "Using a Wiki to Enhance Library Instruction," Indiana Libraries 25, no. 3 (2006): 32

12. Beldarrain, "Distance Education Trends," 140.

13. Matthies et al., "Using a Wiki to Enhance Library Instruction," 32.

14. Keith McPherson, "Wikis and Student Writing," Teacher Librarian 34, no. 2 (Dec. 2006): 70.

15. Achterman, "Beyond Wikipedia," 21.

16. Jeffrey Yan, "Social Technology as a New Medium in the Classroom," The New England Journal of Higher Education 22 (Winter 2008): 29.

17. Ibid., 27.

18. McPherson, "Wikis and Student Writing," 70.

19. Murali Raman et al., "Designing Knowledge Management Systems for Teaching and Learning with Wiki Technology," Journal of Information Systems Education 16, no. 3 (Fall 2005): 311-20.

20. Beldarrain, "Distance Education Trends," 142. 
21. Matthies et al., "Using a Wiki to Enhance Library Instruction," 33.

22. Lamb, "An Information Skills Workout."

23. Vivien E. Zazzau, "Exploring Wikis in a Library Credit Course," Communications in Information Literacy 3 (forthcoming).

24. Tiffany Walsh and Christopher Hollister, ULC-257 Digital Archive, http://libweb.lib.buffalo.edu/wiki/ instruction/ULC257/doku.php (accessed August 28, 2008).

\section{APPENDIX A. PRETEST}

\section{Part 1: Information Competency}

[For questions 1-7, please circle the letter for the correct answer.]

1. Which of the information sources listed below would be most appropriate for answering the following question: "What effects does the thinning of the ozone layer have on the environment?"
a) Map
b) Encyclopedia
c) Directory
d) Periodical index

2. The most current published research on lead poisoning in children can be found in which of the following information sources:
a) Book chapters
b) Bibliographies
c) Gazetteers
d) Journal articles

3. What are the basic concepts from the following question: "Is gender a factor in the rate of school violence?"
a) Boys and Columbine Massacre
b) Sex and peer pressure
c) Sex and school violence
d) Guns and schools

4. The term "periodicals" refers to which of the following information sources:
a) Books, magazines, and newspapers
b) Journals, magazines, and websites
c) Books, journals, and press releases
d) Journals, magazines, and newspapers

5. The online library catalog can be searched to find which of the following:
a) Books and journal articles in the UB Libraries
b) Book holdings for all major research universities
c) Books and journal titles in the UB Libraries
d) Books and journal articles published by UB professors

6. Peer-reviewed journal articles about the "lekking" behavior of hummingbirds can be found in which of the following online information sources:
a) Periodical databases
b) Online library catalog
c) Search engines
d) Web directories

7. Which of the following best describes the Internet?

a) A super-computer that holds an ever-increasing amount of online information

b) A web of interconnected computers hosted by companies, universities, and governments worldwide

c) A network of networks, enabling communication between all computers that are connected worldwide

d) A protocol for communication between servers worldwide 
[For questions 8-12, please mark an " $X$ " next to the correct answer.]

8. True or False: The World Wide Web and the Internet are the same thing.

True

_ False

9. True or False: Most medical information found on the Internet is correct.

True

False

10. True or False: It can be assumed that websites with addresses like www.whitehouse.org and www.martinlutherking.org are reputable sources of information.

True

False

\section{Part 2: Student Opinions}

11. Please offer your opinion ... Instruction on how to become effective and efficient library users should be mandatory for all beginning students at UB.

True

_ False

12. Please offer your opinion... With the advent of Web directories like Yahoo! and search engines like Google, libraries are becoming obsolete.

True

False

\section{APPENDIX B. POSTTEST}

[For questions 1-4, please circle the letter corresponding with the most appropriate answer.]

1. Compare your library research skills today to what they were prior to completing ULC-257. How would you rate those skills?
a) Worse than before
b) No different than before
c) A little better than before
d) Much better than before

2. Given what you have learned in ULC-257, which of the following best describes your current level of expertise in using the library to conduct research?
a) Below average
b) Average
c) Slightly above average
d) Advanced

3. Which of the following best describes your current opinion of library research?

a) There is less to it than I thought prior to taking this class

b) There is more to it than I thought prior to taking this class

c) It is exactly what I thought it was prior to taking this class 
4. Which of the following best describes your opinion of how important academic libraries will be to students in the future?

a) Not important

b) Less important than today

c) More important than today

d) Very important

[For questions 5-10, please place an " $X$ " next the most appropriate answer.]

5. Since completing ULC-257, has your idea of conducting research in the library changed?

Yes

6. Would you recommend ULC-257 to other students?

Y

7. Do you believe that ULC-257 would be a useful course for new or freshman students?

Nos

8. Do you believe that ULC-257 can help to prepare students for their academic careers?

— Yes

9. Can the research skills learned in ULC-257 be applied to all different academic disciplines?

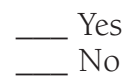

10. Are the skills learned in ULC-257 applicable to students after they have graduated?

Y Yes

\section{APPENDIX C. DIGITAL ARCHIVE STUDENT FEEDBACK FORM}

Regarding ease of use, how would you rate this wiki? Easy, average, or difficult? Please circle one, and feel free to elaborate if you wish.

Your Digital Archive page is an official online publication at the University at Buffalo. Do you feel this is a useful outcome of your coursework? Yes or no? Please circle one, and feel free to elaborate if you wish.

Do you feel comfortable having your coursework publically viewable on the Digital Archive? Yes or no? Please circle one, and feel free to elaborate if you wish.

What are your thoughts on using the Digital Archive in this course? Please explain below. 